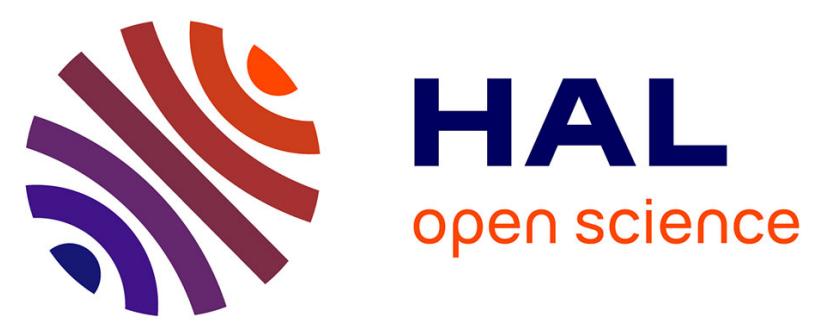

\title{
A Novel Approach for Induced Out-of-season Spawning of Eurasian Perch, Perca fluviatilis
}

Daniel Żarski, Katarzyna Palińska-Żarska, Slawomir Krejszeff, Jaroslaw Król, Sylvain Milla, Pascal Fontaine, Zoltán Bokor, Béla Urbányi

\section{- To cite this version:}

Daniel Żarski, Katarzyna Palińska-Żarska, Slawomir Krejszeff, Jaroslaw Król, Sylvain Milla, et al.. A Novel Approach for Induced Out-of-season Spawning of Eurasian Perch, Perca fluviatilis. Aquaculture, 2019, 512, pp.734300. 10.1016/j.aquaculture.2019.734300 . hal-02300991

\section{HAL Id: hal-02300991 https://hal.science/hal-02300991}

Submitted on 30 Sep 2019

HAL is a multi-disciplinary open access archive for the deposit and dissemination of scientific research documents, whether they are published or not. The documents may come from teaching and research institutions in France or abroad, or from public or private research centers.
L'archive ouverte pluridisciplinaire HAL, est destinée au dépôt et à la diffusion de documents scientifiques de niveau recherche, publiés ou non, émanant des établissements d'enseignement et de recherche français ou étrangers, des laboratoires publics ou privés. 


\title{
A Novel Approach for Induced Out-of-season Spawning of Eurasian Perch,
}

\section{Perca fluviatilis}

Daniel Żarski ${ }^{*}$, Katarzyna Palińska-Żarska ${ }^{2}$, Sławomir Krejszeff ${ }^{3}$, Jarosław Król², Sylvain Milla $^{4}$, Pascal Fontaine ${ }^{4}$, Zoltán Bokor ${ }^{5}$, Béla Urbányi ${ }^{5}$

1. Department of Gametes and Embryo Biology, Institute of Animal Reproduction and Food Research, Polish Academy of Sciences, Tuwima 10, 10-748 Olsztyn, Poland

2. Department of Ichthyology, Faculty of Environmental Sciences, University of Warmia and Mazury, Olsztyn, Poland

3. Department of Aquaculture, The Stanislaw Sakowicz Inland Fisheries Institute, Olsztyn, Poland

4. Team Domestication in Aquaculture, UR AFPA, University of Lorraine, Nancy, France

5. Department of Aquaculture, Szent István University, Gödöllö, Hungary

* Corresponding author: d.zarski@ pan.olsztyn.pl

\begin{abstract}
In this study, the systematic development of a protocol allowing an effective advanced spawning of wild Eurasian perch with the use of salmon gonadoliberin analogue (sGnRHa) was undertaken. The novel approach used in this study involved the application of a strategy of the repeated administration of sGnRHa (i.e., the hormone was given in two doses: priming and resolving) along with an additional thermal stimulation of ovulation. Additionally, the developed protocol was tested for its suitability in the controlled reproduction of domesticated broodstock. The obtained results suggested that the best interval between the hormonal treatments is 7 days when a water temperature of $10^{\circ} \mathrm{C}$ is kept constant between the two injections and when the resolving injection is followed by rapid increments of temperature up to $12^{\circ} \mathrm{C}$, at which spawning is expected. This study revealed that the most suitable priming dose of sGnRHa was $10 \mu \mathrm{g} \mathrm{kg}^{-1}$, at which the highest embryonic survival rates $(>80 \%)$ and
\end{abstract}


spawning efficiency indexes (>500 larvae $\mathrm{kg}^{-1}$ ) (SEI: representing the number of larvae with an inflated swim bladder obtained from $1 \mathrm{~kg}$ of a spawned female) were recorded. Furthermore, in most cases, the application of the resolving injection yielded an embryonic survival rate of over $85 \%$ with the highest ovulation rate $(100 \%)$ and SEI values observed in the group injected with 10 and $25 \mathrm{~g} \mathrm{~kg}^{-1}$ at the priming and resolving doses, respectively. Repeated administrations of sGnRHa were more effective than a previous strategy typically applied for the induction of ovulation in Eurasian perch (a single application of sGnRHa or human chorionic gonadotropin). Moreover, the protocol applied to wild perch can be fully transferrable to domesticated broodstock, which makes it a valuable tool for the improvement of controlled reproduction of this species for intensive aquaculture purposes.

Keywords: Eurasian perch; gonadoliberin analog; controlled reproduction; aquaculture 


\section{Introduction}

Effective controlled reproduction protocols in percids - species that have high importance in the diversification of European freshwater aquaculture (Fontaine, 2009) - are a key to the successful expansion of this developing sector (Żarski et al., 2015, 2019). Despite considerable progress observed within the last three decades, current practices (characterized by a high variability in spawning effectiveness and a considerable extension of the spawning period; Żarski et al., 2017b, 2015) are in need of improvement. This need for improvement is related to a lack of standardized protocols allowing human control over the entire process, which is an indispensable element of intensive aquaculture production planning.

In the controlled reproduction of percids, hormonal treatments are typically applied that allow for considerably synchronized ovulation (Zakęś and Demska-Zakęś, 2009; Żarski et al., 2017b). This practice involves the application of spawning agents when the fish are entering the final oocyte maturation (FOM) stage, which is a process following the vitellogenesis that involves several changes in the oocytes of percids. These changes include germinal vesicle $(\mathrm{GV})$ migration from the center of the oocytes toward the periphery and its subsequent breakdown (GVBD), as well as the creation of a single lipid droplet (Żarski et al., 2012b, 2011). An investigation of this phenomenon in Eurasian perch revealed that during this period, considerable changes in some fatty acids in eggs can occur (Żarski et al., 2012a). Later, it was reported that the type of spawning agent used can modulate FOM and, consequently, affect the final composition of the ovulated eggs (reported to be linked to egg quality; Henrotte et al., 2010). This finding indicates the need for careful reconsideration of the hormonal therapies for this species.

In the controlled reproduction of Eurasian perch, two types of hormonal preparations were used for the induction of ovulation, namely, gonadotropins (GtHs) and gonadoliberin 
analogs (GnRHa), both having different modes of action. The application of GtHs stimulates gonads to produce sex steroids that then control the FOM process, whereas GnRHa triggers the production of endogenous GtHs in the pituitary gland (Mylonas et al., 2010). The most widely applied GtH - human chorionic gonadotropin (hCG) - has a very long half-life (typically several days; Ohta and Tanaka, 1997) in the blood stream following injection compared to GnRHa with a half-life of up to several hours (Zohar et al., 1990). In effect, the application of hCG in percids requires using only a single injection. Interestingly, an additional application (second and even third injection) did not improve spawning effectiveness (for details see: Żarski et al., 2015). In freshwater finfishes, the application of GnRHa usually requires repeating the injection to trigger an additional surge of the hormone and increase the efficiency of such therapy (Kucharczyk et al., 2008b; Targońska et al., 2008). Interestingly, in the scientific literature, a Eurasian perch double-injection strategy using GnRHa-based hormonal preparations was only studied with simultaneous injections of dopamine antagonists (Żarski et al., 2015). Importantly, the application of dopamine antagonists was reported to have an inhibitory effect on ovulation in Eurasian perch (Rónyai and Lengyel, 2010). Moreover, recent findings of Roche et al. (2018) indicate that the application of dopamine antagonists did not have any effect in a closely related species of pikeperch (Sander lucioperca). This result confirms the earlier reports that the application of GnRHa alone is effective in Eurasian perch (Kouril et al., 1997) and pikeperch (Křišt'an et al., 2013; Żarski et al., 2019). However, to date, pure GnRHas were tested only when administered in a single injection in Eurasian perch (Żarski et al., 2015).

In commercial freshwater nonsalmonid Teleostei, the induction of ovulation is based on the application of the hormones in two separate doses, namely, an initial and resolving dose, with the first dose constituting $10-20 \%$ of the entire dose of the hormone applied (Kucharczyk et al., 2008b). This procedure aims at a gentle stimulation of the FOM process, 
allowing for "slow" maturation of the oocytes before ovulation is induced by the resolving dose of the hormone. However, in many cases along with the resolving dose, an additional inducing factor is applied, namely, thermal stimuli, i.e., the temperature is rapidly increased, making it the most probable enhancing potent effect of the hormone. This increased temperature typically leads to highly effective spawning results and high egg quality in a short period of time (e.g., Kucharczyk et al., 2008). To date, such a strategy was not tested in percids.

One of the main problems in the controlled reproduction of Eurasian perch is the synchronization of ovulation. This problem stems from the fact that individual fish, after having completed vitellogenesis, mature unevenly (Żarski, 2012). However, at the beginning of FOM, the vast majority of females are at the same maturation stage (Żarski et al., 2011), which suggests that this asynchronization in maturation between the females occurs mostly during the FOM, not before the FOM. Therefore, from the perspective of controlled reproduction, the beginning of FOM, i.e., maturation stage 1 (Żarski et al., 2011), is the best time to start procedures of hormonal therapy. Considerable synchronization of spawning can be expected by using this method. However, a previous study already reported that classical hormonal treatment strategies (i.e., with the use of hCG) applied to percids at maturation stage I led to reduced egg quality (Żarski et al., 2011), which was probably related to its negative effect on the oocyte composition (Żarski et al., 2017b). Moreover, the application of hCG was reported to increase the level of cortisol following administration (Falahatkar and Poursaeid, 2013), which creates extremely strong concerns for the application of this preparation in cultured fish. Therefore, testing alternative hormonal treatment strategies that lead to improved reproduction protocols and allow for the achievement of a high spawning performance and a high synchronization of ovulation is of highest importance. 
Effective aquaculture of Eurasian perch relies on the reproduction of domesticated broodstock, which is grown exclusively in recirculating aquaculture systems (RAS). These systems allow for obtaining gametes during out-of-season reproduction and supply the juveniles all year round (Fontaine et al., 2015). However, reproductive protocols were mainly developed with the use of wild or pond-reared fish (which is considered a wild-like fish due to its exposure to natural photothermal fluctuations and its foraging on live prey; Żarski et al., 2015) because of very limited access to domesticated breeders. The transfer of knowledge from wild to domesticated fish is often questioned due to the physiological differences reported between the two types of broodstock (Khendek et al., 2017, 2018). To date, there have been no attempts to transfer the protocols developed for wild percids to domesticated stocks.

The aim of the study was to investigate the effectiveness of repeated administrations of GnRHa-based spawning agents, coupled with the thermal stimulation of ovulation, in wild Eurasian perch females during advanced (before the spawning season) reproduction. Additionally, within the study, a validation of a developed protocol in out-of-season reproduction of the domesticated (RAS-grown) broodstock was performed.

\section{Material and methods}

The study complies with international and national regulations for experiments on animals and is in accordance with the permission of local ethical committees No. 76/2013 (issued on 27.11.2013 by the local ethical committee in Olsztyn, Poland, for experiments 1, 2 and 3) and No. 12482-2017120711508699 (issued by the French ethical authorities for experiment 4).

\subsection{Fish origin and broodstock management applied to wild fish}


For Experiments 1, 2 and 3, pond-reared Eurasian perch were obtained from the 'Żurawia' Fish Farm (Biała Rawska, Central Poland) in the middle of October (Experiments 1 and 2, in the first and second year of the study, respectively) or early November (Experiment 3 , in the third year of the study). Fish were transferred to the laboratories of the University of Warmia and Mazury in Olsztyn (northeastern Poland), where they were placed in RAS to allow for the automatic control of the temperature $\left( \pm 0.2^{\circ} \mathrm{C}\right)$ and photoperiod. The RAS where the fish were kept was composed of 6 holding tanks $(300 \mathrm{~L}$ each) made of fiberglass and of a green color. The water was recirculated by passing through a sump tank $(1200 \mathrm{~L})$ in which the chilling system (made of stainless-steel pipes connected to a glycol-based central cooling system) was located. The water from the sump tanks was pumped through a PolyGeyser DF-3 (Aquaculture System Technologies, New Orleans, LA, USA) mechanical-biological filter. The water exchange rate was between 10 and $30 \%$ daily. The system was supplied with tap water. After 7 days of acclimation, fish were exposed to a wintering period. The thermal conditions applied during this period are presented in Fig. 1. During the first two months of wintering, fish were kept in constant dimness (below 4 lx) to reduce stress. After that, light conditions gradually changed to reach the level of $100 \mathrm{~lx}$ at the water surface. During the acclimation of fish to the light conditions, a constant photoperiod was applied, i.e., 14 L:10 D, and these light conditions remained constant until the end of the experiment.

Fish handling was performed each time following anesthesia in a MS-222 solution at a dose of $150 \mathrm{mg} \mathrm{L}^{-1}$.

\subsection{Experiment 1 - the effect of temperature on maturation kinetics following} sGnRHa administration

This experiment was conducted without the presence of males in the tank to avoid potential pheromonal stimulation (Żarski, 2012). For Experiment 1, 50 fish (average weight 
[at the end of the wintering period] of $113 \pm 21 \mathrm{~g}$ ) were used. After the wintering period when the temperature was $8^{\circ} \mathrm{C}$, females were examined for maturation stages using the method described by Żarski et al. (2011). Briefly, a sample of oocytes was taken from each female with a catheter, and each sample was immersed in a clearing solution (a mixture of $70 \%$ ethanol, 38\% formaldehyde and glacial acetic acid in the proportion of 6:3:1). Next, each sample was evaluated using a six-stage classification of oocyte maturation.

Following evaluation of the maturation stages of females, fish were separated according to sex, and for further experiments, only females representing maturation stage 1 were taken. Next, females were individually tagged and randomly divided into three different groups ( $\mathrm{n}=5$ for each group), and each group was put in a different tank with a controlled temperature. Each group was then exposed to a specific temperature, with 8,10 and $12^{\circ} \mathrm{C}$ being target values. In groups intended to be exposed to 10 and $12^{\circ} \mathrm{C}$, the temperature was adjusted with the kinetics of $2^{\circ} \mathrm{C}$ per day.

After two days following wintering, when the temperature reached the target level, fish were injected with $25 \mu \mathrm{g} \mathrm{kg}^{-1}$ of the salmon GnRH analogue (sGnRHa) (amino acid sequence: Pyr-His-Trp-Ser-Tyr-D-Arg-Trp-Leu-Pro-NHEt; Bachem, Switzerland). An average dose was applied in the controlled reproduction of freshwater teleosts (Kucharczyk et al., 2008b). Following hormonal injection, fish from each group were examined for maturation stages (as described above) every 2 days for 14 days. When ovulation was certified (i.e., the egg ribbons were found at the bottom of the tank) the eggs were removed, and the spawned fish were localized and removed from the tank.

\subsection{Experiment 2 - identification of an optimal priming dose of $\mathrm{sGnRHa}$}

Experiment 1 revealed that fish treated at $10^{\circ} \mathrm{C}$ exhibited considerable progression in maturation, but the fish did not ovulate within 8 days, after which the maturation kinetics 
slowed. Therefore, for Experiment 2, a temperature of $10^{\circ} \mathrm{C}$ was chosen as optimal for the priming dose. Considering the maturation kinetics observed during Experiment 1, the period between the priming and resolving dose was established at 7 days. The photoperiod (14 L:10 D) was constant throughout the experiment.

For this experiment, 200 fish (with an average weight of $138 \pm 44 \mathrm{~g}$ at the end of the wintering period) were exposed to the wintering period (as described for Experiment 1). Next, after the temperature was increased to $10^{\circ} \mathrm{C}$, fish were separated according to sex. Next, females were examined for maturation stages (as described earlier), and only females exhibiting stage 1 maturation were chosen for further procedures. At the time of manipulation, females were randomly assigned to one of 7 groups ( $n=10$ for each group): 3 control and 4 experimental groups. Each group was kept in a separate tank (total volume of $300 \mathrm{~L}$, the water in each tank was exchanged every hour) until the end of the experiment. Experimental groups were treated with different priming doses of sGnRHa, namely,: $10,25,50$ and $100 \mu \mathrm{g} \mathrm{kg}^{-1}$ for E2-10, E2-25, E2-50 and E2-100, respectively, whereas control groups were injected with either $0.9 \% \mathrm{NaCl}(\mathrm{C} 2-1$ and $\mathrm{C} 2-2)$ or with sGnRHa (C2-3) (see Tab. 1). The C2-3 group injected with sGnRHa allowed for verification of the effectiveness of such a treatment in only a single dose applied at either the priming or resolving injection. The dose of sGnRHa applied in the C2-3 group $\left(100 \mu \mathrm{g} \mathrm{kg}^{-1}\right)$ was targeted as the highest tested in this study and was chosen on the basis of already published data on the application of GnRHa in percids (Żarski et al., 2015).

After 7 days, the fish were injected with the resolving dose of sGnRHa fixed in all experimental groups at $100 \mu \mathrm{g} \mathrm{kg}^{-1}$. The control groups received either $\mathrm{NaCl}(\mathrm{C} 2-1$ and $\mathrm{C} 2-3)$ or sGnRHa (C2-2) (see Tab. 1). Fifteen running males were placed next to each tank containing females. Males were treated with sGnRHa at a dose of $100 \mu \mathrm{g} \mathrm{kg}^{-1} 5$ days before the resolving injection of the females and maintained at $12^{\circ} \mathrm{C}$, according to the previously 
described protocol (Żarski et al., 2017a). After the resolving injection, the fish were left to spawn spontaneously in the tank to exclude the effect of handling stress from the spawning time (as described by Żarski et al., 2017b). Each tank was examined every $6 \mathrm{~h}$ for the presence of the eggs. After the eggs were detected in the tank, the eggs were collected and put in floating plastic cages for incubation, allowing for effective separate incubations of each portion of the eggs. Observation of the spawning proceeded for 14 days after the resolving injection.

\subsection{Experiment 3 - identification of the optimal resolving dose of $\mathrm{s} G \mathrm{R} \mathrm{RHa}$}

During this experiment, fish ( $\mathrm{n}=265$, average weight of $148 \pm 43 \mathrm{~g}$ at the end of the wintering period) were subjected to the same experimental conditions as in Experiment 2. In the case of the experimental groups (E2-1 to E2-4), the priming dose was chosen on the basis of the results coming from Experiment 2, where $10 \mu \mathrm{g} \mathrm{kg}^{-1}$ was the best. Furthermore, experimental groups were treated with different resolving doses of sGnRHa: 10, 25, 50 and $100 \mu \mathrm{g} \mathrm{kg}^{-1}$ for E3-10, E3-25, E3-50 and E3-100, respectively. Within the control groups, there were two additional groups introduced, treated with hCG $\left(500 \mathrm{IU} \mathrm{kg}^{-1}\right)$ at either the resolving (C3-1) or priming (C3-2) dose, alternating with the application of $\mathrm{NaCl}$. These groups were introduced to compare the effectiveness of the application of alternatives to GnRHa spawning agents in the same conditions. The application of hCG was performed in a single injection, as the long-half-life of this preparation does not require repeated administration. The best control group from Experiment 2 was also included in the experimental design (injection of $100 \mu \mathrm{g} \mathrm{kg}^{-1} \mathrm{sGnRHa}$ along with the resolving injection) (C3-3) along with the new group evaluating the effectiveness of the priming dose $\left(10 \mu \mathrm{g} \mathrm{kg}^{-}\right.$ ${ }^{1}$ of sGnRHa) alone (C3-4). The negative control group (solely treated with $0.9 \% \mathrm{NaCl}$ ) was 
omitted, as no spawning was observed in the previous experiment. The doses and names of the groups are specified in Tab. 2 .

\subsection{Eggs incubation and larval rearing}

In experiments 2 and 3, the eggs were incubated at $14^{\circ} \mathrm{C}$. During the incubation, the embryonic survival rate (calculated from the total number of eggs fertilized) was determined at the eyed-egg stage by the direct counting of viable embryos under a stereo microscope (Zeiss Stereo Discovery V.20, Jena, Germany) in 3 subsamples (approximately 150 eggs) collected from each ribbon. After hatching, the larvae were subjected to the initial rearing procedure according to the protocol described by Palińska-Żarska et al., (2019). For that purpose, larvae were stocked in $20 \mathrm{~L}$ square-shaped, black rearing tanks at a density of 500 ind. $\mathrm{L}^{-1}$ connected to an RAS. The concentrations of ammonia and nitrites in each rearing tank were measured daily with a photometer DR5000 (Hach Lange, Berlin, Germany) and were always below $0.01 \mathrm{mg} \mathrm{L}^{-1}$ for both parameters. The oxygen level was measured twice a day with a Handy Polaris 2.0 (by OxyGuard, Farum, Denmark) and was always above $85 \%$ saturation throughout the rearing period. The $\mathrm{pH}$ values were measured daily with a Handy pH (by Oxyguard, Farum, Denmark) and varied between 7.8 and 8.2.

Larvae coming from different females were pooled within groups and then divided into 3 replicates. The larvae from each group were reared separately. The photoperiod was constant (24 L:0 D) with a light intensity of $1500 \mathrm{~lx}$ at the water surface. The temperature was $15^{\circ} \mathrm{C}$ during the first 12 days of rearing. Next, the temperature was gradually increased to $23^{\circ} \mathrm{C}$ (by $1^{\circ} \mathrm{C}$ per day). The larvae were fed with freshly hatched Artemia sp. nauplii ad libitum from 5 days after hatching. At 20 days post hatch (DPH), the swim bladder inflation effectiveness (SBIE; representing the percentage of larvae with an inflated swim bladder) was calculated for each rearing tank based on approximately 100 randomly caught larvae (in 
triplicate for each tank; in effect, for each group, a minimum of 900 larvae were evaluated) (for a detailed protocol see: Palińska-Żarska et al., 2019). The larvae total length (TL) and wet body weight (WBW) were determined at the beginning and at the end of the rearing trial. WBW was determined $( \pm 0.1 \mathrm{mg})$ with the use of a precision balance (Kern ABJ 120-4M, Germany) according to the method described by Krejszeff et al., (2013), whereas TL was determined under a stereo-microscope (Zeiss steREO Discovery V.20, Jena, Germany) with the use of AxioVision (Zeiss) software. The entire larval rearing procedure allowed for calculating the spawning efficiency index (SEI), representing the number of larvae with an inflated swim bladder, which was obtained from $1 \mathrm{~kg}$ of ovulating females. This calculation was performed to estimate the final differences in the production of high-quality larvae from different groups during the entire operation.

\subsection{Experiment 4 -application of the elaborated hormonal treatment protocol in} an out-of-season reproduction of domesticated stock

Domesticated perch broodstock (F3 generation; age 2+; average weight $204 \pm 36 \mathrm{~g}$ ) was obtained from the Asialor (Pierrevillers, France) fish farm. Fish that had never spawned before, after acclimation, were exposed to a 9 months photothermal program at the Aquaculture Experimental Platform (PEA) of URAFPA of the University of Lorraine (Nancy, France), where they were placed in $1500 \mathrm{~L}$ rectangular tanks operating in RAS. The photothermal program used was the program previously described by Fontaine et al., (2015) with a small modification provided at the end of the program; this modification included an arresting temperature at $10^{\circ} \mathrm{C}$ following the wintering period, and the thermal regime was maintained during the spawning period analogous to the regime developed during Experiments 1 and 2 (Fig. 2). The doses applied (10 $\mu \mathrm{g} \mathrm{kg}^{-1}$ and $25 \mu \mathrm{g} \mathrm{kg}^{-1}$, for the priming and resolving doses, respectively) were based on the results of Experiments 2 and 3. Fish 
were fed until apparent satiation with commercial feed (47\% protein, $13 \%$ fat, $1.9 \%$ cellulose, $11 \%$ ash, $14 \%$ starch, $1.5 \%$ phosphorus) throughout the study. Females, following the priming injection until the end of the experiment, were kept separate from males. At both the priming and resolving injections, the fish were examined for maturation stages (as described in Experiment 1). Males were injected along with the priming dose of the hormone at a dose of $100 \mu \mathrm{g} \mathrm{kg}^{-1}$ (as previously reported by Żarski et al., 2017a).

Following the application of the resolving dose, the fish were subjected to a typical commercial spawning operation involving examining the females for ovulation every $6 \mathrm{~h}$. When the ovulation was certified, fish were stripped into dry plastic containers, the spawning time was recorded, and the eggs were then fertilized with freshly collected pooled sperm coming from 3 males. For each $100 \mathrm{~g}$ of the obtained eggs, $1 \mathrm{~mL}$ of sperm was used.

From each egg portion obtained, following fertilization, two egg subsamples $(n=$ $\sim 150$ eggs) were taken and then incubated separately at $14^{\circ} \mathrm{C}$ in experimental incubators (in duplicates for each fish). At $72 \mathrm{~h}$ post fertilization, direct counting of the developing and nondeveloping embryos in each egg sample was conducted under a stereomicroscope. Next, during the hatching period every day, hatched larvae were removed from the incubator and were counted and preserved in $4 \%$ formaldehyde for further evaluation of deformity occurrence (as described by Alix et al., 2017). This experimental procedure allowed for determining the latency time from the time of the priming injection until ovulation and determining the egg quality indicators (embryonic survival, hatching [both calculated from the total number of eggs fertilized] and deformity rates [calculated from the total number of larvae hatched]) that had not been assessed in the 3 previous experiments due to the necessity of performing tank spawning aimed at a reduction of the stress to the wild fish. In Experiment 4, conversely, the SEI was not determined due to the lack of a specific small-scale larvae 
rearing system allowing an application of the previously implemented (in Experiments 2 and 3) rearing procedure.

\subsection{Data analysis and statistics}

All the data are presented as the mean $\pm \mathrm{SD}$. Data expressed in percentages were arcsine-root-square-transformed prior to statistical analysis. Next, the data were examined for homogeneity of variance with the Levene test. If the data were normally distributed (tested with Shapiro-Wilk test), they were subsequently tested with analysis of variance (ANOVA) to determine their potential significant differences, followed by Duncan's post hoc test. Otherwise, the data (maturation stages, ovulation rates, latency time, deformity rates, larval survival rates, SBIE, SEI) were analyzed with the Kruskal-Wallis nonparametric test followed by the Mann-Whitney test to determine whether the comparisons were significant. The data were compared at the significance level of $\mathrm{P}<0.05$. The data were analyzed with MS Excel for Windows and Statistica 13 software (StatSoft).

\section{Results}

3.1. Experiment 1 - the effect of temperature on maturation kinetics following sGnRHa administration

Females initially recognized at maturation stage 1 progressed in maturation following hormonal treatment in a temperature dependent manner. At $12^{\circ} \mathrm{C}$, females progressed in maturation significantly faster $(\mathrm{P}<0.05)$ on days 2 and 4 when compared to fish maintained at 8 and $10^{\circ} \mathrm{C}$, respectively. Two fish ovulated on day 6 following the hormonal injection. At this temperature (i.e., $12^{\circ} \mathrm{C}$ ), all the females ovulated by day 12 following the injection. A lower temperature (i.e., $10^{\circ} \mathrm{C}$ ) caused a slower progression in maturation and 
promoted ovulation in only one female on day 12 following the injection. Fish maintained at $10^{\circ} \mathrm{C}$ were already exhibiting a more advanced maturation stage $(\mathrm{P}<0.05)$ than the fish kept at $8^{\circ} \mathrm{C}$ on the second day following injection. At the lowest temperature applied $\left(8^{\circ} \mathrm{C}\right)$, none of the females matured beyond stage 3 (Fig. 3). Therefore, for further experiments, the temperature of $10^{\circ} \mathrm{C}$ was chosen as a temperature suitable to promote $\mathrm{FOM}$ after the priming dose of the hormone, as it promoted considerable progression of maturation without ovulation within the first 10 days of a trial. Additionally, a rule was established that the resolving injection should be applied 7 days after the priming injection, which coincided with a slowed down progression in maturation noticeable after that period.

\subsection{Experiment 2 - identification of the optimal priming dose of $\mathrm{s} G \mathrm{RH} \mathrm{Ha}$}

Within the considered period of time, none of the nonhormonally treated fish ovulated. Therefore, this group was excluded from further analysis. Fish group C2-2 (injected with $100 \mu \mathrm{g} \mathrm{kg}^{-1}$ in a second injection) ovulated the latest $(\mathrm{P}<0.05)$, whereas group $\mathrm{C} 2-3$ (injected along with the priming dose) only ovulated at a time similar to the experimental groups (Tab. 1). In terms of the embryonic survival rate, the highest values (over 90\%) $(\mathrm{P}<0.05)$ were recorded after the application of the lowest dose of sGnRHa $\left(10 \mu \mathrm{g} \mathrm{kg}^{-1}\right)$. Among the remaining groups, only in group E2-50 was a comparable embryonic survival rate recorded. Despite there being no differences in the initial and final characteristics of the larvae (in terms of the WBW, TL, SBIE and survival rate of the larvae), the number of viable eggs obtained significantly affected the SEI, which was the highest in group E2-10. However, the SEI recorded in the E2-10 group was only significantly higher $(\mathrm{P}<0.05)$ than the $\mathrm{C} 2-2$ group, whereas no significant differences among the remaining groups were recorded (Tab. 1).

\subsection{Experiment 3 - identification of an optimal resolving dose of $\mathrm{sGnRHa}$}


The application of hCG along with only the resolving dose (in group C3-1) allowed for the collection of eggs from $80 \%$ of the females within approximately 7 days post injection (i.e., $~ 14$ days counted from the time of the priming injection), which was comparable to the latency time recorded for the $\mathrm{C} 3-3$ group $(\mathrm{P}>0.05)$ (Tab. 2). However, despite the eggs being characterized by a considerably high embryonic rate, the number of larvae obtained from the C3-1 group was insufficient to evaluate the larval performance. In effect, this group was excluded from further analysis. Fish treated with hCG at only the priming dose (C3-2) ovulated within a similar period of time as all the experimental groups, whereas the control group injected with $10 \mu \mathrm{g} \mathrm{kg}^{-1}$ of sGnRHa at the priming dose (C3-4) ovulated earlier than the C3-1 and C3-3 groups but later than the remaining groups $(\mathrm{P}<0.05)$. The highest embryonic survival rate (ranging between 86.3 and 92.3\%) was recorded in experimental groups treated with 10,25 and $50 \mu \mathrm{g} \mathrm{kg}^{-1}$ of sGnRHa in the resolving dose, whereas the lowest values were noted in the control groups as well as the group treated with the highest resolving dose (i.e., E3-100) (between 56.8 and 72.3\%). Despite the lack of differences between all the groups in terms of WBW and TL $(\mathrm{P}>0.05)$ at the beginning and end of the rearing trial, there were considerable differences in terms of the recorded SBIE, where the highest values were observed in groups E3-10, E3-25 and E3-50 and among which no significant differences were noted $(\mathrm{P}>0.05)$. When considering SBIE, the lowest values were found in the C3-2 and E3100 groups. The highest SEI values were recorded again in groups where fish were injected with 10,25 and $50 \mu \mathrm{g} \mathrm{kg}^{-1}$ of sGnRHa during the resolving injection, and they were significantly higher than the values observed in the remaining groups $(\mathrm{P}<0.05)$ (Tab. 2).

\subsection{Experiment 4 - application of the elaborated hormonal treatment protocol in out-of-season reproduction of domesticated stock}


An applied photothermal program allowed the obtainment of fully functional spawners of Eurasian perch. The vast majority of the fish were at stage 1 of FOM at the time of the priming injection as was expected. At the time of second injection, fish were in maturation stage 4 or 5 . Only 1 out of the 12 fish did not ovulate. The fish ovulated between 192 and $246 \mathrm{~h}$ from the moment of the priming injection. An evaluation of egg quality indices indicated high developmental competences of the obtained eggs (expressed in terms of the embryonic survival and hatching rates), although a considerably high deformity rate of hatched larvae was also observed (Tab. 3).

\section{Discussion}

In this study, the systematic development of a double-injection hormonal treatment strategy for the induction of ovulation during an advanced spawning operation in Eurasian perch is being described for the first time. Notably, this newly developed protocol allowed for obtaining high quality larvae from pond-reared fish in January (3 months prior to the spawning season), which has never been described before. In addition, the first ever transfer of a reproductive protocol developed for the wild-like population to a domesticated broodstock in percids has been successfully undertaken.

In the case of Eurasian perch, a double-injection strategy had so far only been tested with the use of either gonadotropins (hCG and carp pituitary homogenate $[\mathrm{CPH}]$ ) or GnRH analogues, with the latter being always administered with dopamine antagonists (Żarski et al., 2015) and having a negative effect on the reproduction effectiveness in Eurasian perch (Rónyai and Lengyel, 2010). Interestingly, even among other percid species, a doubleinjection strategy was rarely tested. For example, the application of the mammalian GnRH analogue in yellow perch (Perca flavescens) was always administered along with pimozide (a dopamine antagonist) given in a first injection (Ciereszko et al., 1997; Dabrowski et al., 
1994). Among all the percids, only in the case of walleye (Sander vitreum) (Malison et al., 1998) and most recently in pikeperch (Żarski et al., 2019) was GnRHa given in double injection without any additives. In all the papers published to date on the application of a double-injection strategy in percids, a lack of improvement of spawning effectiveness was observed. Therefore, for many years, a single injection was considered the most suitable way to stimulate ovulation in percids. However, in all the previous studies on Eurasian perch, the resolving injection was always given $24 \mathrm{~h}$ after the priming dose (Żarski et al., 2015). Moreover, among the studies on reproduction of percid fishes, only in one study was the interval between injections longer than $48 \mathrm{~h}$ (i.e., $72 \mathrm{~h}$; Lessman, 1978). The results of Experiment 1 of this study have revealed that maturation kinetics following the priming dose are highly dependent on the temperature. Therefore, in determining the interval between injections, which is crucial in supporting the effectiveness of hormonal stimulation, two main factors should be considered - temperature and the maturation stage upon injection. The typically applied temperature during the induced spawning of perch (i.e., $12^{\circ} \mathrm{C}$ ) in this study promoted a considerably rapid maturation when compared to $10^{\circ} \mathrm{C}$. However, even at $12^{\circ} \mathrm{C}$, $24 \mathrm{~h}$ intervals seemed to be unsuitable for causing maturation to progress to ovulation, which excluded the need for repeated administration. Therefore, by applying two injections at $12^{\circ} \mathrm{C}$ with a $24 \mathrm{~h}$ interval, minimal improvement in terms of synchronization of ovulation can be expected.

In the case of percids, the thermal stimulation of ovulation coupled with the administration of hormones has never been tested, although it is common practice in other freshwater teleosts (Krejszeff et al., 2009; Kucharczyk et al., 2008b; Targońska et al., 2010). During the induced spawning of Eurasian perch, the temperature ranged between 10 and $19^{\circ} \mathrm{C}$, depending on the study (Żarski et al., 2015). However, the most commonly recommended temperature in the last few years in this species is $12^{\circ} \mathrm{C}$ (e.g., Żarski et al., 
2017b). Therefore, by evaluating the kinetics of maturation following the priming dose in Experiment 1 of this study, using $10^{\circ} \mathrm{C}$ during the administration of the priming dose was the most reasonable approach. At this temperature, the maturation stage of fish steadily grew for approximately 1 week, meaning that the effect of the administration of GnRHa was expected to last for such a period. In effect, the results of this study have revealed that when a doubled administration of the hormones is considered, much longer time intervals (than the $48 \mathrm{~h}$ interval that has been tested so far among percids) should be applied when temperatures between 10 and $12^{\circ} \mathrm{C}$ are chosen. However, other thermal regimes can be potentially suggested for application, although careful evaluation of the maturation kinetics following the priming dose should be performed first.

The results obtained in this study indicate that a double-injection strategy along with the thermal regimes applied allowed for synchronized ovulation in Eurasian perch during the advanced spawning where most of the fish ovulated within $24 \mathrm{~h}$. When sGnRHa was administered in only 1 dose after the temperature rose (as in groups C2-2 and C3-3), as is typically done in Eurasian perch, a lower embryonic survival rate was observed, which is in accordance with previous reports on the advanced spawning of this species (Szczerbowski et al., 2009; Targońska et al., 2014; Żarski et al., 2017b). Therefore, the treatment protocol proposed in this study provided a considerable improvement of the entire spawning operation. Notably, the results of SEI obtained in Experiment 2 were approximately 40 times lower than the values recorded in Experiment 3 (comparing Tab. 1 and Tab. 2). Such a large difference probably stemmed from the fact that fish in Experiment 2 were taken into the hatchery too early (almost 1 month earlier than in Experiment 3 ) as the overall wintering duration has a significant effect on the advanced spawning effectiveness in this species (Szczerbowski et al., 2009). Therefore, when the advanced spawning of Eurasian perch is considered, the spawning time should not be planned earlier than the end of January or the beginning of February. 
Earlier attempts to induce ovulation may allow for obtaining eggs but with a high probability of lower performance from the larvae coming out of the eggs.

The application of only a single injection of sGnRHa coupled with increments of temperature (as it was performed in groups C2-3 and C3-4) caused delayed spawning compared to the experimental groups due to the lower temperature applied during the initial phases of FOM. The lower spawning effectiveness (i.e., a higher embryonic survival rate and SEI) observed in those groups when compared to the highest-performing groups (E2-10 and E3-25 in Experiment 2 and 3, respectively) suggests the lower efficiency of such a hormonal strategy. This observation additionally justifies the application of an advanced spawning Eurasian perch protocol where thermal stimulation following the application of GnRHa is coupled along with the additional application of the resolving dose of the hormone.

The application of hCG in a single injection, regardless of the thermal regime, allowed for obtaining eggs within a reasonably short period of time. However, a lower egg quality was the highest concern, especially in that the application of hCG after increments of temperature led to the hatching of very few larvae. Notably, this study aimed for obtaining not only eggs but also larvae in the earliest time ever reported (at the beginning or end of January, in Experiment 2 and 3 respectively), which has never been accomplished to date. Therefore, this typical hormonal treatment (single injection of hCG) allowed for obtaining viable embryos but very few larvae. This result is probably linked with the significant modulation of the biochemical composition of the ovulated eggs when hCG is applied at very early maturation stages in this species (Żarski et al., 2017b). However, although lower temperatures negatively affected egg quality, the results of this study allowed for suspicions that the thermal manipulation may improve the hormonal treatment protocols with the application of GtHs. Nonetheless, more studies are needed to verify whether a constant lower temperature may reduce the negative effect of hCG on egg quality when applied at maturation stage 1. 
Previous studies on reproductive performance usually evaluated spawning effectiveness by investigating the ability of the eggs to be fertilized and develop to a certain developmental stage, mostly before larvae were capable of hatching (Kouril et al., 1997; Kucharczyk et al., 1998, 1996). This especially concerns studies on advanced or out-of-season spawning where the survival rates of embryos at the eyed-egg stage were usually investigated (Szczerbowski et al., 2009; Targońska et al., 2014; Żarski et al., 2017b). However, there is no report of how the larvae would possibly perform when obtained several months (in this case 3 months) prior to the natural spawning season. Kucharczyk et al. (2008a) reported that the larvae of common carp (Cyprinus carpio) obtained during the advanced spawning were significantly smaller than it was suggested they would be, which was related to the shorter period of gonadogenesis affecting the size of the larvae. However, in our study, freshly hatched larvae obtained along with the larvae from after 20 days of rearing had similar sizes to those obtained during the spawning season (Palińska-Żarska et al., 2019). In effect, the results of this study indicate for the first time that larvae obtained in advance of the spawning season (several months before the natural spawning season) are fully functional material for intensive aquaculture purposes. In addition, the possibility of shortening the gonadal cycle by 3 months creates perspectives of much more efficient utilization of broodstock, which can be spawned more frequently than every 12 months. However, this possibility requires further studies with the use of domesticated stocks.

During the domestication process, fish, together with the adaptation to the culture environment, deviated in terms of gonadal development and physiological responses to photothermal manipulations (Khendek et al., 2018, 2017). This phenomenon puts in question the effectiveness of the potential transfer of reproductive protocols developed based on wild (or wild-like, similar to the protocols used in this study) fish to the domesticated stocks. The most recent study by Żarski et al. (2019) suggested that domesticated pikeperch broodstock 
responded to hormonal treatment in a very similar manner to the wild fish. This suggestion is in accordance with the data presented in this study, where the protocol developed for wild fish was successfully implemented in a controlled reproduction of domesticated stock. The obtained eggs were characterized by high developmental competence, although the deformity rate of hatched larvae were quite high compared to the other studies on RAS-grown Eurasian perch (<5\% was reported by Alix et al., 2017). However, a very similar deformity rate of the larvae (as in the present study) was reported by (Żarski et al., 2019) for domesticated pikeperch where ovulation was also induced by sGnRHa. In the study of Alix et al. (2017), eggs were collected without hormonal treatments, which suggests the involvement of the hormonal treatment in inducing deformities of the larvae. However, following hormonal induction, over $90 \%$ fish ovulated, whereas there is no information about the ovulation rate in the study of Alix et al. (2017). In effect, following hormonal stimulation, most of the fish are likely capable of spawning, including the fish yielding lower egg quality and/or leading to high deformity of the larvae. The fish in both considered studies originated from different fish farms, which also suggests the involvement of either a genetic factor or husbandry practices. Therefore, even though the controlled reproduction of domesticated stock in this study was fully successful, a specific validation procedure should be undertaken whenever any kind of reproductive protocol will be transferred to commercially grown fish, as some differences may still exist between the stocks, stemming from different photothermal regimes and/or other factors (including factors not recognized yet), potentially influencing the spawning performance and egg quality.

The results presented in this study clearly indicate that the combination of temperature and hormonal stimulation may be a very useful tool in the optimization and finetuning of reproductive protocols in percids. The protocol developed in this study is highly effective in inducing ovulation during an advanced spawning operation of Eurasian perch. 
The application of GnRHa allowed for improving the spawning effectiveness when compared to the application of the typically-used hCG, which was found in this study to have reduced effectiveness. This result was also confirmed previously (e.g., Żarski et al., 2011). Additionally, the protocol was also highly useful in the case of domesticated broodstock, which is the first proof of the transferability of reproductive protocols between wild and domesticated stocks in percids.

\section{Acknowledgements}

This study was financed by the EUREKA project "Development of an induce spawning technology and hatchery manual for the Eurasian perch (Perca fluviatilis)", (E! 8028 PERCAHATCH). Additional funding was received from the European Union's Horizon 2020 research and innovation programme under grant agreement No. 652831 (AQUAEXCEL ${ }^{2020}$ ). This output reflects only the authors' view and the European Union cannot be held responsible for any use that may be made of the information contained herein.

\section{References}

Alix, M., Żarski, D., Chardard, D., Fontaine, P., Schaerlinger, B., 2017. Deformities in newly hatched embryos of Eurasian perch populations originating from two different rearing systems. J. Zool. 302, 126-137. https://doi.org/10.1111/jzo.12447

Ciereszko, R.E., Dabrowskl, K., Ciereszko, A., Ebeling, J., Ottobre, J.S., 1997. Effects of temperature and photoperiod on reproduction of female yellow perch Perca flavescens: plasma concentrations of steroid hormones, spontaneous and induced ovulation, and quality of eggs. J. World Aquac. Soc. 28, 344-356. https://doi.org/10.1111/j.17497345.1997.tb00281.x

Dabrowski, K., Ciereszko, A., Ramseyer, L., Culver, D., Kestemont, P., 1994. Effects of hormonal treatment on induced spermiation and ovulation in the yellow perch (Perca flavescens). Aquaculture. 120, 171-180. https://doi.org/10.1016/0044-8486(94)90231-3

Falahatkar, B., Poursaeid, S., 2013. Effects of hormonal manipulation on stress responses in male and female broodstocks of pikeperch Sander lucioperca. Aquac. Int. 22, 235-244. https://doi.org/10.1007/s10499-013-9678-x

Fontaine, P., 2009. Développement de la pisciculture continentale européenne et domestication de nouvelles espèces. Cah. Agric. 18, 144-147.

https://doi.org/10.1684/agr.2009.0288 
Fontaine, P., Wang, N., Hermelink, B., 2015. Broodstock management and control of the reproductive cycle, in: Kestemont, P., Dąbrowski, K., Summerfelt, R.C. (Eds.), Biology and Culture of Percid Fishes. Springer, Dordrecht, Netherlands, pp. 103-122. https://doi.org/10.1007/978-94-017-7227-3_3

Henrotte, E., Kaspar, V., Rodina, M., Psenicka, M., Linhart, O., Kestemont, P., 2010. Dietary n-3/n-6 ratio affects the biochemical composition of Eurasian perch (Perca fluviatilis) semen but not indicators of sperm quality. Aquac. Res. 41, e31-e38. https://doi.org/10.1111/j.1365-2109.2009.02452.x

Khendek, A., Alix, M., Viot, S., Ledoré, Y., Rousseau, C., Mandiki, R., Kestemont, P., Policar, T., Fontaine, P., Milla, S., 2017. How does a domestication process modulate oogenesis and reproduction performance in Eurasian perch? Aquaculture. 473, 206-214. https://doi.org/10.1016/j.aquaculture.2017.02.003

Khendek, A., Chakraborty, A., Roche, J., Ledoré, Y., Personne, A., Policar, T., Żarski, D., Mandiki, R., Kestemont, P., Milla, S., Fontaine, P., 2018. Rearing conditions and life history influence the progress of gametogenesis and reproduction performances in pikeperch males and females. Animal. 12, 2335-2346. https://doi.org/10.1017/S1751731118000010

Kouril, J., Linhart, O., Relot, P., 1997. Induced spawning of perch by means of a GnRH analogue. Aquac. Int. 5, 375-377.

Krejszeff, S., Targonska, K., Zarski, D., Kucharczyk, D., 2009. Domestication affects spawning of the ide (Leuciscus idus) — preliminary study. Aquaculture. 295, 145-147. https://doi.org/10.1016/j.aquaculture.2009.06.032

Krejszeff, S., Żarski, D., Palińiska-Zarska, K., Trabska, I., Kupren, K., Targońska, K., Bowszys, M., Kucharczyk, D., 2013. Procedure for harmless estimation of fish larvae weight. Ital. J. Anim. Sci. 12, 270-274. https://doi.org/10.4081/ijas.2013.e44

Křišt'an, J., Alavi, S.M.H., Stejskal, V., Policar, T., 2013. Hormonal induction of ovulation in pikeperch (Sander lucioperca L.) using human chorionic gonadotropin (hCG) and mammalian GnRH analogue. Aquac. Int. 21, 811-818. https://doi.org/10.1007/s10499012-9572-y

Kucharczyk, D., Kujawa, R., Murmurz, A., Skrzypczak, A., Wyszomirska, E., 1996. Induced spawning in perch, Perca fluviatilis L. using carp pituitary extract and HCG. Aquac. Res. 27, 847-852. https://doi.org/10.1046/j.1365-2109.1996.t0-1-00802.x

Kucharczyk, D., Kujawa, R., Mamcarz, A., Skrzypczak, A., Wyszomirska, E., 1998. Induced spawning in perch, Perca fluviatilis L., using FSH + LH with pimozide or metoclopramide. Aquac. Res. 29, 131-136. https://doi.org/10.1046/j.13652109.1998.00949.x

Kucharczyk, D., Targońska, K., Hliwa, P., Gomułka, P., Kwiatkowski, M., Krejszeff, S., Perkowski, J., 2008a. Reproductive parameters of common carp (Cyprinus carpio L) spawners during natural season and out-of-season spawning. Reprod. Biol. 8, 285-289. https://doi.org/10.1016/S1642-431X(12)60018-7

Kucharczyk, D., Targońska, K., Żarski, D., Kujawa, R., Mamcarz, A., 2008b. A review of the reproduction biotechnology for fish from the genus Leuciscus. Arch. Pol. Fish. 16, 319340. https://doi.org/10.2478/s10086-008-0021-5

Lessman, C.A., 1978. Effects of gonadotropin mixtures and two steroid on inducing ovulation in the walleye. Progress. Fish-Cult. 40, 3-5. 
Malison, J.A., Procarione, L.S., Kayes, T.B., Hansen, J.F., Held, J.A., 1998. Induction of outof-season spawning in walleye (Stizostedion vitreum). Aquaculture 163, 151-161. https://doi.org/10.1016/S0044-8486(98)00220-8

Mylonas, C.C., Fostier, A., Zanuy, S., 2010. Broodstock management and hormonal manipulations of fish reproduction. Gen. Comp. Endocrinol. 165, 516-534. https://doi.org/10.1016/j.ygcen.2009.03.007

Ohta, H., Tanaka, H., 1997. Relationship between serum levels of human chorionic gonadotropin (hCG) and 11-ketotestosterone after a single injection of hCG and induced maturity in the male Japanese eel, Anguilla japonica. Aquaculture 153, 123-134. https://doi.org/10.1016/S0044-8486(97)00020-3

Palińska-Żarska, K., Krejszeff, S., Łopata, M., Żarski, D., 2019. Effect of water hardness, temperature, and tank wall color, on the effectiveness of swim bladder inflation and survival of Eurasian perch (Perca fluviatilis, L.) larvae reared under controlled conditions. Aquac. Int. https://doi.org/10.1007/s10499-018-0333-4

Roche, J., Żarski, D., Khendek, A., Ben Ammar, I., Broquard, C., Depp, A., Ledoré, Y., Policar, T., Fontaine, P., Milla, S., 2018. D1, but not D2, dopamine receptor regulates steroid levels during the final stages of pikeperch gametogenesis. Animal. 12, 25872597. https://doi.org/10.1017/S1751731118000824

Rónyai, A., Lengyel, S.A., 2010. Effects of hormonal treatments on induced tank spawning of Eurasian perch (Perca fluviatilis L.). Aquac. Res. 41, e345-e347. https://doi.org/10.1111/j.1365-2109.2009.02465.x

Szczerbowski, A., Kucharczyk, D., Mamcarz, A., Łuczyński, M.J., Targońska, K., Kujawa, R., 2009. Artificial off-season spawning of Eurasian perch Perca fluviatilis L. Arch. Pol. Fish. 17, 95-98.

Targońska, K., Żarski, D., Kucharczyk, D., 2008. A review of the artificial reproduction of asp, Aspius aspius (1.), and nase, Chondrostoma nasus (1.). Arch. Pol. Fish. 16, 341-354 https://doi.org/10.2478/s10086-008-0022-4

Targońska, K., Kucharczyk, D., Kujawa, R., Mamcarz, A., Żarski, D., 2010. Controlled reproduction of asp, Aspius aspius (L.) using luteinizing hormone releasing hormone (LHRH) analogues with dopamine inhibitors. Aquaculture. 306, 407-410. https://doi.org/10.1016/j.aquaculture.2010.05.027

Targońska, K., Szczerbowski, A., Żarski, D., Łuczyński, M.J., Szkudlarek, M., Gomułka, P., Kucharczyk, D., 2014. Comparison of different spawning agents in artificial out-ofseason spawning of Eurasian perch, Perca fluviatilis L. Aquac. Res. 45, 765-767. https://doi.org/10.1111/are.12010

Zakęś, Z., Demska-Zakęś, K., 2009. Controlled reproduction of pikeperch Sander lucioperca (L.): a review. Arch. Pol. Fish. 17, 153-170. https://doi.org/10.2478/v10086-009-0014-z

Żarski, D., Bokor, Z., Kotrik, L., Urbanyi, B., Horváth, A., Targońska, K., Krejszeff, S., Palińska, K., Kucharczyk, D., 2011. A new classification of a preovulatory oocyte maturation stage suitable for the synchronization of ovulation in controlled reproduction of Eurasian perch Perca fluviatilis L. Reprod. Biol. 11, 194-209. https://doi.org/10.1016/S1642-431X(12)60066-7

Żarski, D., 2012. First evidence of pheromonal stimulation of maturation in Eurasian perch, Perca fluviatilis L., females. Turk. J. Fish. Aquat. Sci. 12, 771-776.

Żarski, D., Krejszeff, S., Horváth, Á., Bokor, Z., Palińska, K., Szentes, K., Łuczyńska, J., 
Targońska, K., Kupren, K., Urbányi, B., Kucharczyk, D., 2012a. Dynamics of composition and morphology in oocytes of Eurasian perch, Perca fluviatilis L., during induced spawning. Aquaculture. 364-365, 103-110. https://doi.org/10.1016/j.aquaculture.2012.07.030

Żarski, D., Kucharczyk, D., Targońska, K., Palińska, K., Kupren, K., Fontaine, P., Kestemont, P., 2012b. A new classification of pre-ovulatory oocyte maturation stages in pikeperch, Sander lucioperca (L.), and its application during artificial reproduction. Aquac. Res. 43, 713-721. https://doi.org/10.1111/j.1365-2109.2011.02879.x

Żarski, D., Horváth, A., Held, J.A., Kucharczyk, D., 2015. Artificial reproduction of percid fishes, in: Kestemont, P., Dąbrowski, K., Summerfelt, R.C. (Eds.), Biology and Culture of Percid Fishes. Springer, Dordrecht, Netherlands, pp. 123-161. https://doi.org/10.1007/978-94-017-7227-3_4

Żarski, D., Bernáth, G., Król, J., Cejko, B.I., Bokor, Z., Palińska-Żarska, K., Milla, S., Fontaine, P., Krejszeff, S., 2017a. Effects of hCG and salmon gonadoliberine analogue on spermiation in the Eurasian perch (Perca fluviatilis). Theriogenology. 104, 179-185. https://doi.org/10.1016/j.theriogenology.2017.08.022

Żarski, D., Palińska-Żarska, K., Łuczyńska, J., Krejszeff, S., 2017b. The type of spawning agent affects the egg composition during out-of-season spawning but not during inseason spawning in Eurasian perch, Perca fluviatilis. Gen. Comp. Endocrinol. 245, 1929. https://doi.org/10.1016/j.ygcen.2016.04.027

Żarski, D., Fontaine, P., Roche, J., Alix, M., Blecha, M., Broquard, C., Król, J., Milla, S., 2019. Time of response to hormonal treatment but not the type of a spawning agent affects the reproductive effectiveness in domesticated pikeperch, Sander lucioperca. Aquaculture. 503, 527-536. https://doi.org/10.1016/j.aquaculture.2019.01.042

Zohar, Y., Goren, A., Fridkin, M., Elhanati, E., Koch, Y., 1990. Degradation of gonadotropinreleasing hormones in the gilthead seabream, Sparus aurata: II. cleavage of native salmon GnRH, mammalian LHRH, and their analogs in the pituitary, kidney, and liver. Gen. Comp. Endocrinol. 79, 306-319. https://doi.org/10.1016/0016-6480(90)90116-4 
Tab. 1. Characterization of hormonal treatment protocols applied in Control (C) and Experimental (E) groups during the Experiment 2 as well as results obtained during the advanced spawning of pond-reared Eurasian perch and rearing trial of the larvae. For methodical details see Section 3.2. All the data are expressed as mean $( \pm \mathrm{SD})$. Data in rows marked with different letter index were statistically different $(\mathrm{P}<0.05)$.

\begin{tabular}{|c|c|c|c|c|c|c|c|c|}
\hline \multicolumn{2}{|l|}{ Name of a group } & \multirow{2}{*}{$\begin{array}{l}\mathrm{C} 2-1 \\
0.9 \% \mathrm{NaCl}\end{array}$} & \multirow{2}{*}{$\begin{array}{l}\mathrm{C} 2-2 \\
0.9 \% \mathrm{NaCl}\end{array}$} & \multirow{2}{*}{$\begin{array}{l}\text { C2-3 } \\
\text { sGnRHa }\end{array}$} & \multirow{2}{*}{$\begin{array}{l}\text { E2-10 } \\
\text { sGnRHa }\end{array}$} & \multirow{3}{*}{$\begin{array}{l}\text { E2-25 } \\
\text { sGnRHa } \\
25 \mu \mathrm{g}\end{array}$} & \multirow{3}{*}{$\begin{array}{l}\text { E2-50 } \\
\text { sGnRHa } \\
50 \mu \mathrm{g}\end{array}$} & \multirow{3}{*}{$\begin{array}{l}\text { E2-100 } \\
\text { sGnRHa } \\
100 \mu \mathrm{g}\end{array}$} \\
\hline Priming dose & Spawning agent & & & & & & & \\
\hline \multirow{3}{*}{ Resolving dose } & Dose (per kg of body weight) & $1 \mathrm{ml}$ & $1 \mathrm{ml}$ & $100 \mu \mathrm{g}$ & $10 \mu \mathrm{g}$ & & & \\
\hline & Spawning agent & $0.9 \% \mathrm{NaCl}$ & sGnRHa & $0.9 \% \mathrm{NaCl}$ & \multicolumn{4}{|c|}{ sGnRHa } \\
\hline & Dose (per kg of body weight) & $1 \mathrm{ml}$ & $100 \mu \mathrm{g}$ & $1 \mathrm{ml}$ & \multicolumn{4}{|c|}{$100 \mu \mathrm{g}$} \\
\hline \multicolumn{2}{|c|}{ Ovulation rate $(\%)$} & - & 60 & 70 & 70 & 70 & 40 & 60 \\
\hline \multicolumn{2}{|c|}{ Latency time $(\mathrm{h})$} & - & $320 \pm 38^{c}$ & $239 \pm 61^{\mathrm{b}}$ & $201 \pm 22^{\mathrm{a}}$ & $195 \pm 12^{\mathrm{a}}$ & $219 \pm 11^{\mathrm{a}}$ & $206 \pm 11^{\mathrm{a}}$ \\
\hline \multicolumn{2}{|c|}{ Embryonic survival rate $(\%)$} & - & $30.3 \pm 31.4^{\mathrm{b}}$ & $41.3 \pm 21.2^{\mathrm{b}}$ & $80.7 \pm 11.7^{\mathrm{a}}$ & $32.5 \pm 24.3^{\mathrm{b}}$ & $53.0 \pm 21.5^{\mathrm{ab}}$ & $24.2 \pm 23.9^{b}$ \\
\hline \multicolumn{2}{|c|}{ Initial length of larvae (mm) } & & $5.9 \pm 0.2$ & $5.8 \pm 0.3$ & $5.9 \pm 0.2$ & $5.8 \pm 0.2$ & $5.9 \pm 0.3$ & $5.9 \pm 0.4$ \\
\hline \multicolumn{2}{|c|}{ Initial weight of larvae (mg) } & & $1.2 \pm 0.2$ & $1.2 \pm 0.2$ & $1.3 \pm 0.3$ & $1.2 \pm 0.3$ & $1.1 \pm 0.2$ & $1.2 \pm 0.2$ \\
\hline \multicolumn{2}{|c|}{$\operatorname{SBIE}(\%)^{*}$} & - & $27.7 \pm 7.8$ & $26.9 \pm 13.3$ & $27.0 \pm 5.3$ & $30.6 \pm 4.4$ & $29.5 \pm 9.9$ & $31.9 \pm 11.2$ \\
\hline \multicolumn{2}{|c|}{ Survival rate of larvae (\%) } & - & $29.6 \pm 8.7$ & $26.9 \pm 9.9$ & $27.3 \pm 6.0$ & $25.6 \pm 8.2$ & $26.9 \pm 9.6$ & $27.3 \pm 8.4$ \\
\hline \multicolumn{2}{|c|}{ Final total length of larvae (mm) } & & $12.1 \pm 0.9$ & $13.1 \pm 0.1$ & $12.5 \pm 0.2$ & $12.0 \pm 0.3$ & $12.7 \pm 0.2$ & $12.2 \pm 0.1$ \\
\hline \multicolumn{2}{|c|}{ Final total weight of larvae (mg) } & - & $13.4 \pm 0.9$ & $13.1 \pm 1.1$ & $13.0 \pm 1.2$ & $12.9 \pm 1.8$ & $13.1 \pm 1.1$ & $12.9 \pm 0.8$ \\
\hline \multicolumn{2}{|c|}{ SEI** } & - & $424 \pm 78^{b}$ & $460 \pm 37^{\mathrm{ab}}$ & $524 \pm 37^{\mathrm{a}}$ & $490 \pm 96^{\mathrm{ab}}$ & $459 \pm 66^{\mathrm{ab}}$ & $478 \pm 116^{\mathrm{ab}}$ \\
\hline
\end{tabular}

*SBIE - swim bladder inflation effectiveness

**SEI - spawning efficiency index (representing number of larvae with inflated swim bladder obtained from $1 \mathrm{~kg}$ of spawned female) 
Tab. 2. Characterization of hormonal treatment protocols applied in Control (C) and Experimental (E) groups during the Experiment 3 as well as results obtained during the advanced spawning of pond-reared Eurasian perch and rearing trial of the larvae. For methodical details see Section 3.2. All the data are expressed as mean $( \pm \mathrm{SD})$. Data in rows marked with different letter index were statistically different $(\mathrm{P}<0.05)$.

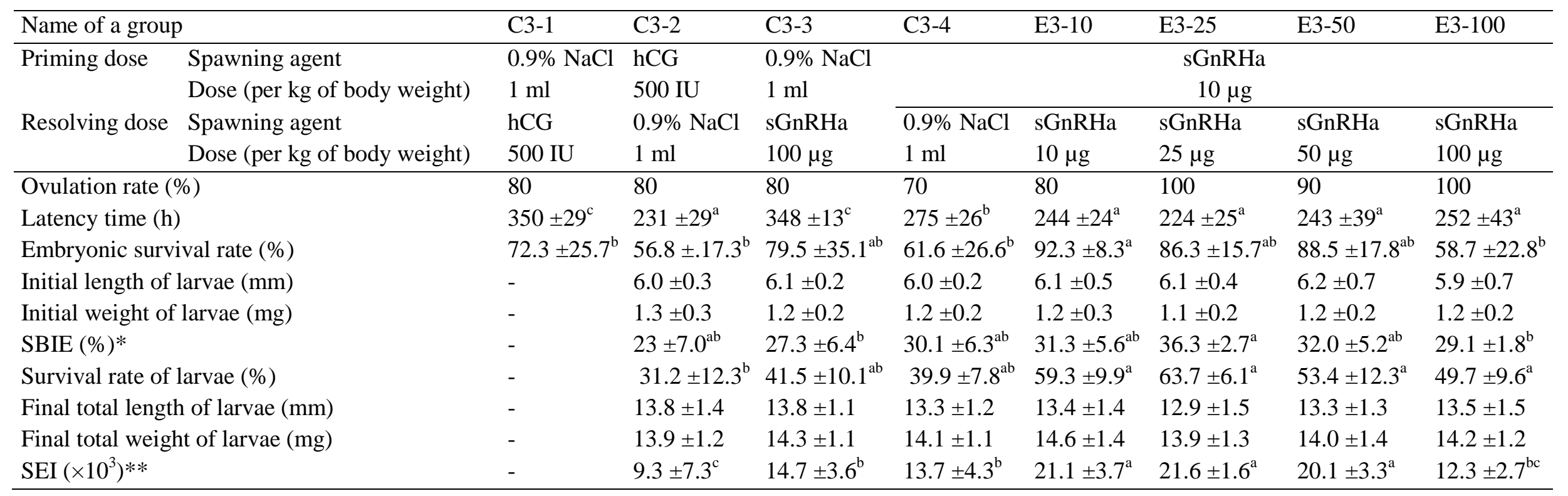

*SBIE - swim bladder inflation effectiveness

**SEI - spawning efficiency index (representing number of larvae with inflated swim bladder obtained from $1 \mathrm{~kg}$ of spawned female) 
Tab. 3. Results of controlled reproduction and reproductive effectiveness of domesticated Eurasian perch following application of repeated administration of sGnRHa for induction of ovulation during the out-of-season spawning. Priming dose $\left(10 \mu \mathrm{g} \mathrm{kg}^{-1}\right)$ was given 7 days before resolving dose $\left(25 \mu \mathrm{g} \mathrm{kg}^{-1}\right)$. Temperature between injections was $10^{\circ} \mathrm{C}$. After resolving dose temperature was gradually increased $\left(<1{ }^{\circ} \mathrm{C}\right.$ per h) up to $12^{\circ} \mathrm{C}$ which was held constant until the end of the operation.

\begin{tabular}{lcccc}
\hline & Mean & SD & Min & Max \\
\hline Maturation stage at 1st injection* & 1.1 & 0.2 & 1.0 & 2.0 \\
Maturation stage at 2nd injection* & 4.9 & 0.5 & 4.0 & 5.0 \\
Latency time following priming dose (h) & 218 & 17 & 192 & 246 \\
Ovulation rate (\%) & 92 & - & - & - \\
Embryonic survival rate (\%) & 82.9 & 17.7 & 42.9 & 97.6 \\
Hatching rate (\%) & 69.3 & 25.2 & 25.5 & 93.0 \\
Deformity rate (\%) & 20.9 & 16.7 & 5.7 & 57.9 \\
\hline
\end{tabular}

*According to the 6-stage classification described by Żarski et al. 2011. 


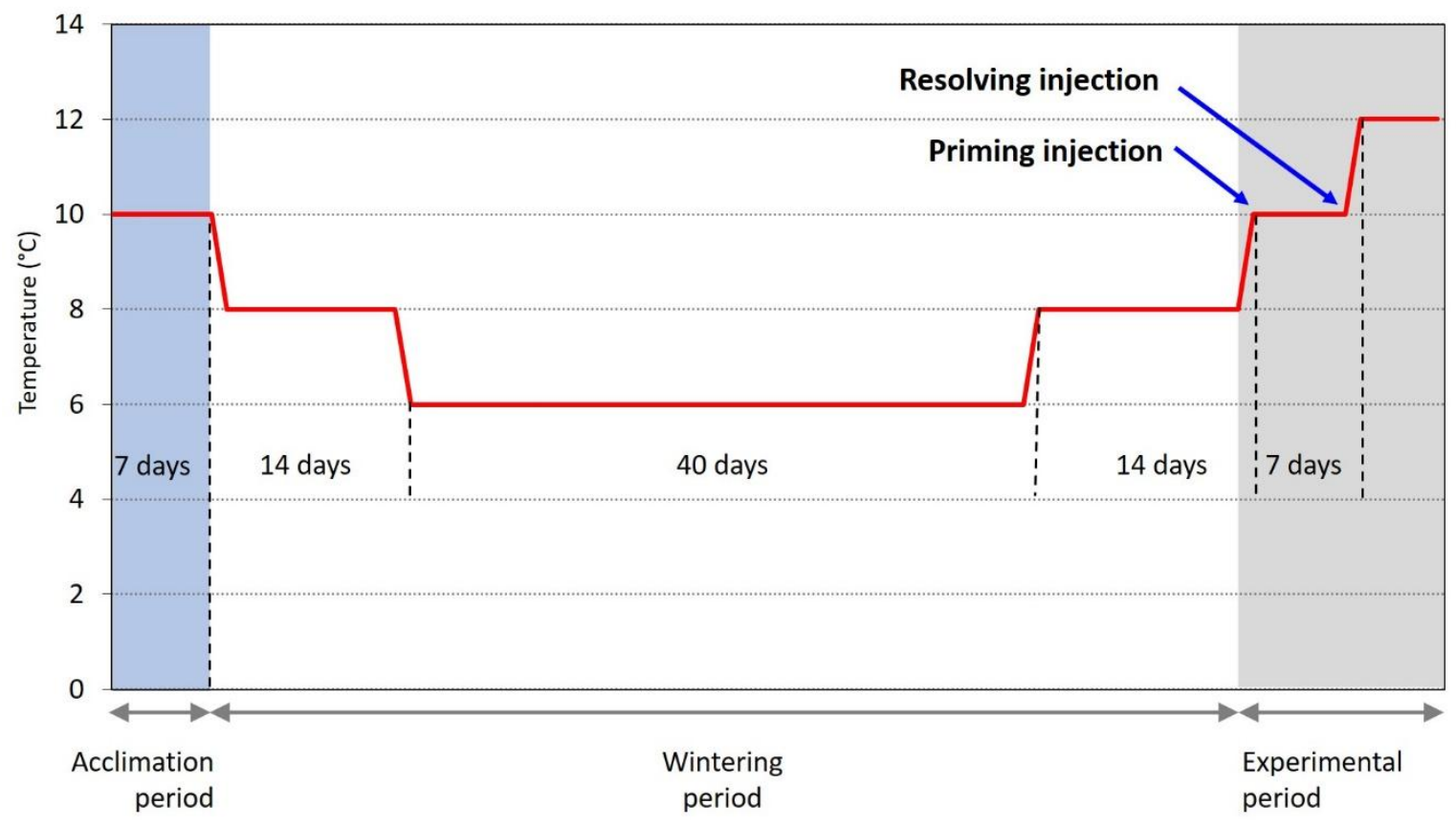

Fig. 1. Thermal regime applied during the acclimation, wintering and spawning period of pond-reared Eurasian perch. Arrows indicate the time of the application of hormonal treatment. Wintering period refer to the period when the fish were exposed to the temperature below $10^{\circ} \mathrm{C}$. Priming and resolving injections were different for different experiments (for details see Tab. 1 and 2). 


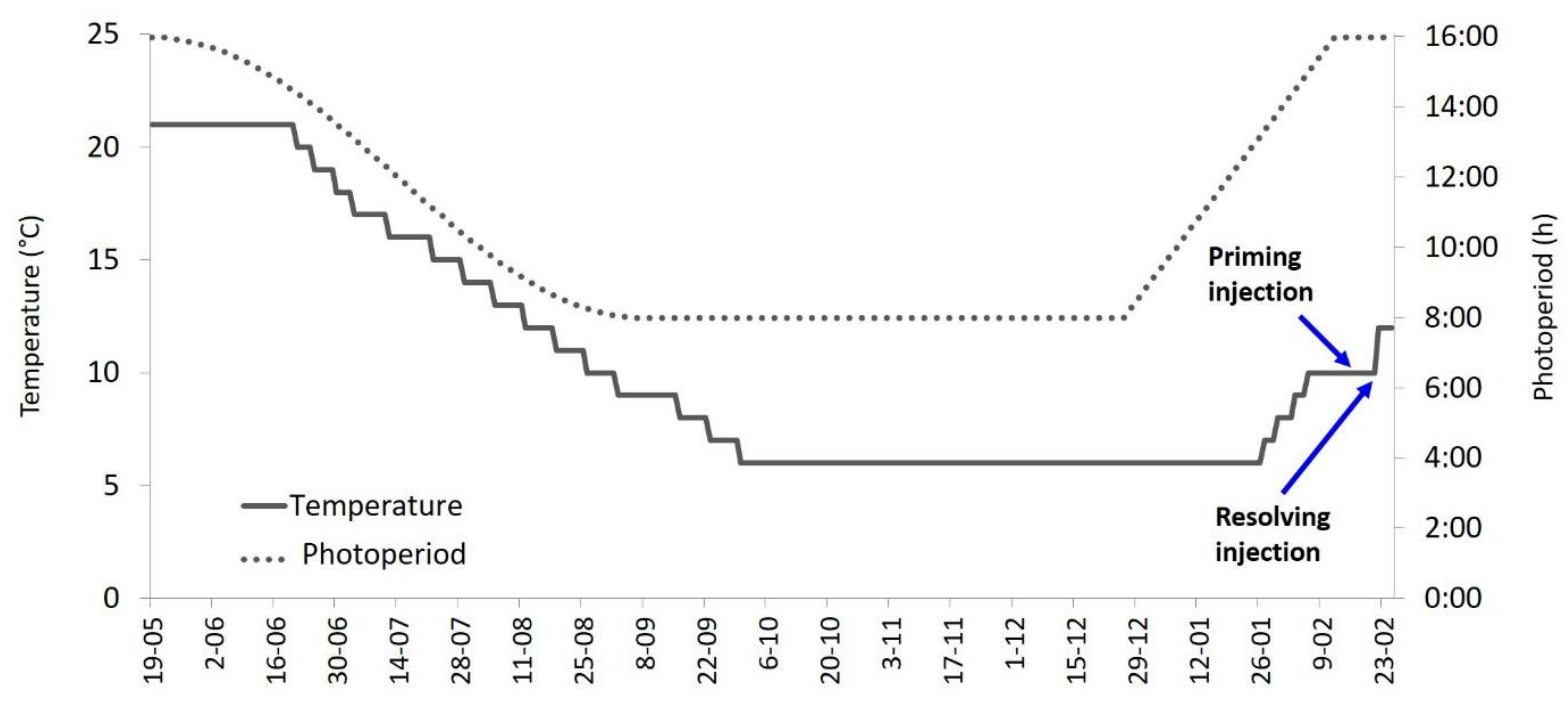

Fig. 2. Photo-thermal applied during induction of gonadogenesis and spawning in domesticated Eurasian perch (after Fontaine et al. 2015 - modified). Arrows indicate the time of application of novel hormonal treatment elaborated during the study where 10 and $25 \mu \mathrm{g} \mathrm{kg}$ ${ }^{1}$ of salmon gonadoliberine analogue ( $\mathrm{sGnRHa}$ ) was applied during the priming and resolving injection, respectively. 


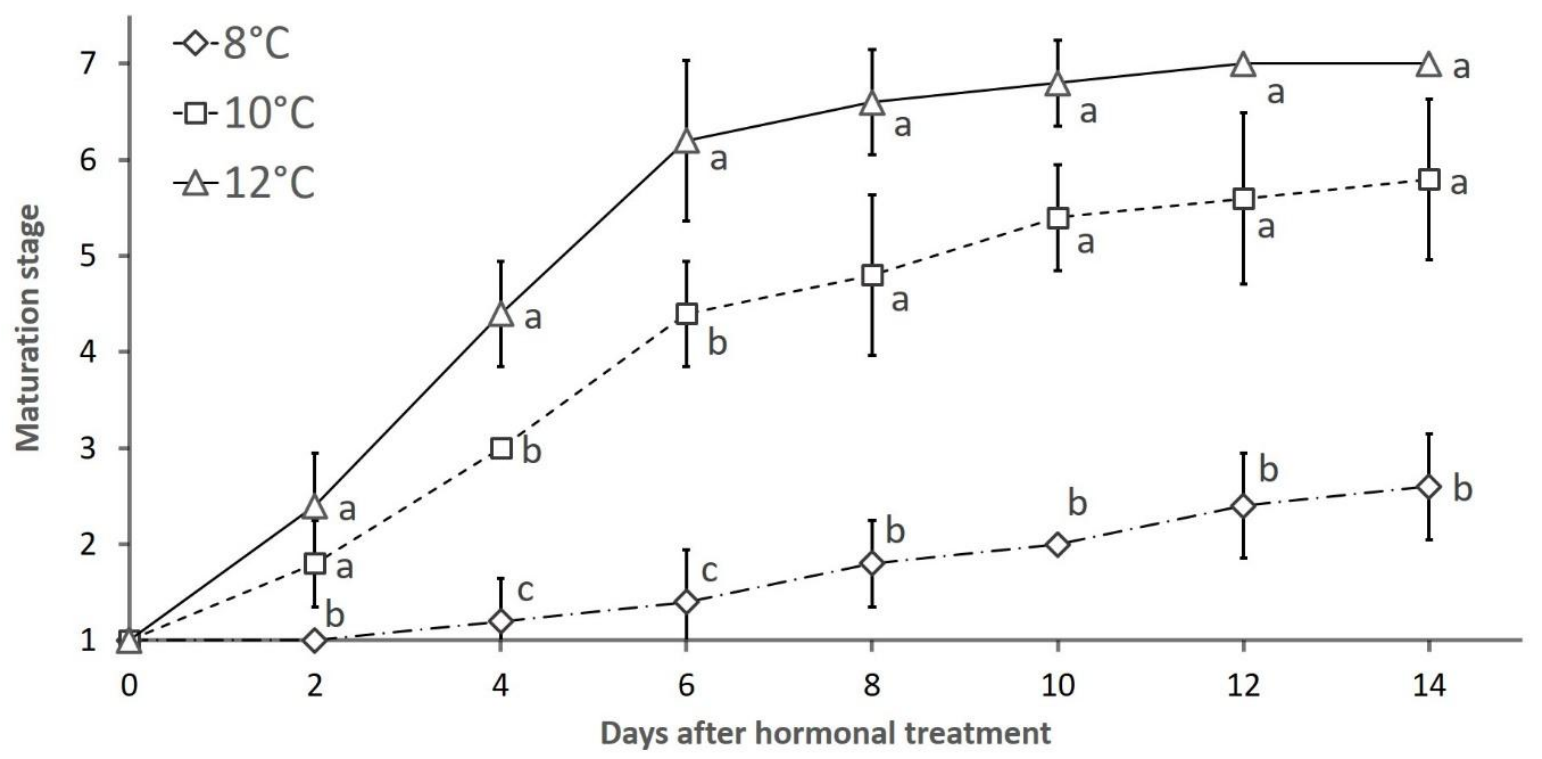

Fig. 3. Kinetics of maturation stages of females ( $\mathrm{n}=5$ for each group) injected $100 \mu \mathrm{g} \mathrm{kg}^{-1}$ of sGnRHa and kept at different temperatures. Maturation stages on axis ' $y$ ' represent six preovulatory stages and additional stage 7 represents ovulated eggs (as described by Żarski et al. 2011). 